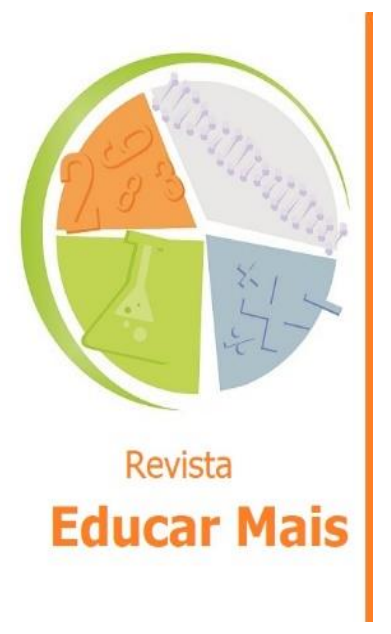

\title{
ELASTICIDADE DO SOCIAL: A Relação saúde- educação e o disciplinamento dos corpos docente/discente impostos pela Pandemia COVID-19 na cultura pantaneira.
}

\section{SOCIAL ELASTICITY: The health-education relationship and the discipline of faculty/students imposed by the COVID-19 Pandemic in Pantanal culture}

ELASTICIDAD DE LO SOCIAL: La Relación salud- educación y el disciplinamento de los cuerpos docente/dicente impuestos por la Pandamia COVID-19 en la cultura pantanera.

David Arenas Carmona1; Janete Rosa da Fonseca²; Priscila Rosa da Fonseca ${ }^{3}$

\section{RESUMO}

No início do ano de 2020, a mudança nas relações sociais foi extrema e provocou um novo reordenamento não só das relações, mas de corpos e de uma série de sentimentos extremos, como medo, ansiedade, insegurança entre outros. Este estudo teve origem a partir desse contexto vivenciado no início do referido ano, com o surgimento da Pandemia da COVID -19 o que suscitou o desenvolvimento de uma pesquisa que visa investigar a marcação nos corpos dos sujeitos que circulam na educação superior na região do pantanal sulmatogrossense. Objetivou-se para tanto discutir a luz das contribuições de teóricos dos Estudos Culturais, como esse processo de disciplinamento de corpos se dá, como respondem a o que foi imposto, a essa mudança que, de repente, trouxe mais períodos dentro de casa, longe da natureza. Verificar como e se as relações com a família nos períodos de isolamento social promoveram alguma interferência no estímulo para permanecer desenvolvendo suas atividades profissionais e acadêmicas e identificar as dificuldades apresentadas pelos sujeitos participantes da pesquisa (discentes/docentes) no processo de ajustar o próprio corpo aos imperativos temporais do período vivenciado. Dessa forma a pesquisa pretendeu apresentar um recorte entre a relação saúde, educação e a disciplina que nos foi imposta pela pandemia na tentativa de promover um olhar sobre o que discentes e docentes do Ensino Superior da região do Pantanal sul mato-grossense, enfatizando os desafios da contemporaneidade no campo do lazer, esperam do que, como nos traz Boaventura (2020), ficou convencionado chamar de "novo normal".

Palavras-chave: Cultura Pantaneira; Disciplinamento; Pandemia

\section{ABSTRACT}

At the beginning of 2020, the change in social relationships was extreme and caused a new reorganization not only of relationships, but of bodies and a series of extreme feelings, such as fear, anxiety, insecurity, among others. This study originated from this context experienced at the beginning of that year, with the emergence of the COVID-19 Pandemic, which prompted the development of a research that aims to investigate the marking on the bodies of subjects who circulate in higher education in the wetland region. Mato Grosso do Sul. The objective was to discuss the light of the contributions of Cultural Studies theorists, how this process of

${ }^{1}$ Licenciado em Pedagogia, Especialista em Docência para o Ensino Superior e Mestre em Geografia. Professor da Universidade Federal do Mato Grosso do Sul/Campus de Aquidauana. Vice-líder do Grupo de Pesquisa em Estudos Decoloniais-GPED. E-mail: dav.are.car@gmail.com

${ }^{2}$ Licenciada em Pedagogia, Mestre em Estudos Culturais na Educação e Doutora em Educação. Docente do Programa de Pós-graduação em Estudos Culturais- PPGCult da Universidade Federal de Mato Grosso do Sul/ Campus de Aquidauana. Líder do Grupo de Pesquisa em Estudos Decoloniais (GPED). E-mail: janete.fonseca@ufms.br

${ }^{3}$ Médica pela Universidade Federal de Pelotas (UFPEL). Pós-graduada em Endocrinologia pela Faculdade IPEMED de Ciências Médicas - São Paulo. E-mail: pri.rosadafonseca@gmail.com 
disciplining bodies takes place, how they respond to what was imposed, to this change that suddenly brought more periods at home, away from the nature. Check how and whether relationships with the family in periods of social isolation promoted some interference in the stimulus to continue developing their professional and academic activities and identify the difficulties presented by the subjects participating in the research (students/professors) in the process of adjusting their own body to the temporal imperatives of the experienced period. Thus, the research intended to present a cut between the relationship between health, education and the discipline that was imposed on us by the pandemic in an attempt to promote a look at what students and teachers of Higher Education in the Pantanal region of southern Mato Grosso do, emphasizing the challenges from contemporaneity in the field of leisure, they expect what, as Boaventura (2020) brings us, was agreed to call the "new normal."

Keywords: Pantanal Culture; Discipline; Pandemic.

\section{RESUMEN}

En el inicio del año 2020, la mudanza en las relaciones sociales fué extrema y provoco un nuevo reordenamiento, no sólo de las relaciones, sino de los cuerpos y de una serie de sentimientos extremos como miedo, ansiedad, inseguridad entre otros. Este estudio tuvo origen a partir de ese contexto vivenciado con el surgimiento de la Pandemia de COVID-19, lo que suscitó el desarrollo de una pesquisa que visa investigar la marca en los cuepos de los sujetos que circulan en la región del pantanal sur-matogrossense. Objetivose, para tanto, discutir a la luz de las contribuciones de teóricos de los estudios culturales, como este proceso de disciplinamento de cuerpos se dá, como responden a lo impuesto, a la mudanza que, repentinamente, trajo más períodos dentro de casa, lejos de la naturaleza. Verificar como y si las relaciones con la familia en los períodos de aislamiento social promovieron algunas interferencias en el estímulo para permanecer desarrollando sus actividades profesionales y académicas e identificar las dificultades presentadas por los sujetos participantes de la pesquisa (dicentes/docentes) en el proceso de ajustar el propio cuerpo a los imperativos temporales del período vivenciado. De esta forma, la pesquisa pretendió presentar un recorte entre la relación salud, educación y la disciplina que fué impuesta por la Pandemia en la tentativa de promover una mirada sobre lo que dicentes y docentes de la Enseñanza Superior de la región del Pantanal Sul-matrogrossense, enfatizando los desafíos de la contemporaneidad en el campo de la recreación, de lo que, como dice Boaventura (2020), quedó convencionado en llamar de "nuevo normal".

Palabras clave: Cultura pantanera. Disciplinamiento. Pandemia.

\section{INTRODUÇÃO}

As mudanças na forma de se relacionar e conviver em sociedade costumam sofrer alterações ao longo dos tempos. Isso acontece de forma quase natural, até mesmo imperceptível, porém no início do ano de 2020, a mudança nas relações sociais foi extrema e provocou um novo reordenamento não só das relações, mas de corpos e de uma série de sentimentos extremos, como medo, ansiedade, insegurança entre outros. Este estudo teve origem a partir desse contexto vivenciado no início do ano de 2020, com o surgimento da Pandemia da COVID -19 o que suscitou o desenvolvimento de uma pesquisa que visa investigar a marcação nos corpos dos sujeitos que circulam na educação superior na região do pantanal sul-matogrossense. A covid-19 é a doença causada pelo vírus SARS-CoV-2, doença essa que se caracteriza por uma inflamação aguda das vias aéreas, podendo ocorrer de forma leve ou até assintomática, mas que também pode evoluir de forma bastante grave, até o óbito.

O SARS-CoV- 2 é um betacoronavírus da família Coronaviridae, e é o sétimo coronavírus identificado, com potencial de infectar o ser humano.

O SARS-CoV-2 foi identificado primeiramente, em pacientes com quadro respiratório na cidade de Wuhan, na China. De acordo com dados da Organização Mundial de Saúde - OMS, em janeiro de 2020, foi comunicada pelas autoridades chinesas a descoberta desse novo vírus. Inicialmente o novo 
vírus recebeu a denominação de 2019-nCov, a qual foi substituída pela nomenclatura atual em 11 de fevereiro de 2020.

Como citado anteriormente o SARS-CoV-2 é o vírus causador da Covid-19, doença que teve seus primeiros casos na China, e em março de 2020, alcançou status de pandemia, declarado pela OMS. Vale ressaltar que a definição de pandemia, se refere à distribuição geográfica da doença, e é declarada quando o surto de uma nova doença se propaga em escala mundial.

No mês de julho de 2021, a estimativa mundial de casos, gira em torno dos 190 milhões. A transmissão do novo coronavírus se dá através do contato com gotículas de saliva da pessoa portadora do vírus, o que pode ocorrer através de tosse, espirros, da própria fala com proximidade, além do toque seguido de contato das mãos com olhos, nariz e boca. Por essa forma de contágio, a pandemia de covid-19 vem modificando de modo severo as relações interpessoais.

Iremos abordar a mudança nestas relações, ocorridas especificamente na região do Pantanal sulmatogrossense. Quando se busca uma definição para os sujeitos que habitam a região do Pantanal, encontramos a definição de que estes se caracterizam por serem moradores dessa região há várias gerações, possuindo costumes e cultura próprios, influenciados diretamente pelas relações estabelecidas com o meio ambiente. Como os sujeitos da pesquisa estão acostumados a ter o hábito do contato direto com o outro, através de costumes que são próprios de sua organização social, como as rodas de Tereré, os encontros em festas típicas da região, as reuniões ao ar livre, lidaram e lidam com seus sentimentos e qual a influência desse afastamento de uma vida social culturalmente institucionalizada na região do Pantanal, no desempenho profissional e educacional desses sujeitos, constitui-se na questão norteadora dessa investigação.

Objetiva-se para tanto discutir a luz das contribuições de Foucault (2014) entre outros teóricos dos Estudos Culturais, como esse processo de disciplinamento de corpos se dá, como respondem a esse processo que foi imposto, a essa mudança que, de repente, trouxe mais períodos dentro de casa, longe da natureza. Verificar como e se as relações com a família nos períodos de isolamento social promoveram alguma interferência no estímulo para permanecer desenvolvendo suas atividades profissionais e acadêmicas e identificar as dificuldades apresentadas pelos sujeitos participantes da pesquisa (discentes/docentes) no processo de ajustar o próprio corpo aos imperativos temporais do período vivenciado. Dessa forma a pesquisa pretende apresentar um recorte entre a relação saúde, educação e a disciplina que nos foi imposta pela Pandemia na tentativa de promover um olhar sobre o que discentes e docentes do Ensino Superior da região do Pantanal sul mato-grossense, enfatizando os desafios da contemporaneidade no campo do lazer esperam do que, como nos traz Boaventura (2020), ficou convencionado chamar de "novo normal". Em um primeiro momento abordamos o conceito de cultura e a construção da identidade dos sujeitos que habitam o bioma Pantanal sul matogrossense, denominados "pantaneiros". Na sequência buscou-se promover uma reflexão sobre a disciplina que se fez necessária na tentativa de conter o avanço da pandemia, as mudanças de hábitos. Trazemos à tona conceitos como o disciplinamento de corpos evidenciado por Foucault (2014) e ousamos parafrasear Boaventura de Sousa Santos (2020) ao nos referirmos aos termos "elasticidade do social."

Ainda compondo o arcabouço teórico de nossa investigação, nos dedicamos a tecer considerações acerca da identidade cultural dos sujeitos ancorados nas contribuições de Stuart Hall (2011) e Homi K. Bhabha (1998). Os caminhos metodológicos nos levaram para a Etnometodologia o que nos possibilitou uma aproximação com questões do cotidiano que foram alteradas na rotina dos sujeitos 
da pesquisa e que nos resultados e discussão vieram a comprovar que nosso recorte entre saúde e educação e a disciplina que nos foi imposta pela pandemia na tentativa de nos adequarmos na luta pela sobrevivência, adaptando nossos corpos, nossos hábitos culturais e nossas relações profissionais e pessoais vem exercendo um grande impacto e provavelmente virá a se transformar em um dos grandes desafios da contemporaneidade no que tange ao restabelecimento do que estamos chamando de novo normal, tanto no campo do lazer, saúde , educação e relações interpessoais como podemos evidenciar dos resultados e discussões as considerações finais aqui apresentadas.

\title{
2. REFERENCIAL TEÓRICO
}

\subsection{A estreita relação entre o bioma do pantanal e a identidade cultural dos sujeitos pantaneiros.}

Quando se aborda uma temática centrada na cultura, várias representações do significado da expressão cultura ${ }^{4}$ emergem. Vamos nos permitir trazer para iniciar esta reflexão, o conceito de cultura que nos apresenta Marconi e Presotto.

\begin{abstract}
A cultura, pode ser analisada, ao mesmo tempo, sob vários enfoques: ideias (conhecimento e filosofia); crenças (religião e superstição); valores (ideologia e moral); normas (costumes e leis); atitudes (preconceito e respeito ao próximo) padrões de conduta (monogamia, tabu); abstração do comportamento (símbolos e compromissos); instituições (família e sistemas econômicos); técnicas (artes e habilidades); e artefatos (machado de madeira, pedra, telefone). Os artefatos decorrem da técnica, mas a sua utilização é condicionada pela abstração do comportamento. As instituições ordenam os padrões de conduta que decorrem de atitudes condicionadas em normas e baseadas em valores determinados tanto pelas crenças quanto pelas ideias. (MARCONI E PRESOTTO, 2005, p.24)
\end{abstract}

Nos parece muito amplo o conceito de cultura, mas também podemos discutir acerca da localização da cultura, de sua essência, classificação e componentes. No que se refere a esta pesquisa, podemos inferir que quanto a localização estamos abordando acontecimentos que constituem a cultura de um povo de uma determinada região do Brasil. E que poderia se caracterizar como interorgânica, uma vez que falamos dos processos de interação social entre os sujeitos que devido a Pandemia da COVID19 sofrem profundas alterações. Já quando o assunto é a essência da cultura, vale lembrar que os comportamentos, podem ser conceituados como modos de agir comuns a determinados grupos em face ao meio social que estão inseridos.

"O comportamento dos sujeitos é influenciado pelos padrões da cultura em que vive". (MARCONI E PRESOTTO, 2005, p.34). Dessa maneira se compreende claramente quando se chega a um determinado local e se percebe até mesmo na arquitetura do lugar que existe um padrão, um padrão cultural daquele grupo. Então podemos perceber que os sujeitos tomam para si diferentes elementos de uma cultura e passam a agir de acordo com os padrões daquele grupo social que se sentem pertencentes. Como já ficou claro a cultura se estabelece na relação social, nasce da relação dos sujeitos com a natureza que os cerca.

Nesta pesquisa ancoramos nossas investigações na cultura "pantaneira", o pantanal, segundo Nogueira (1989), constitui-se de vários pantanais, formados pelo Rio Paraguai e seus afluentes que acabam por caracterizar a vegetação do lugar, a fauna, as condições do solo e a vida daqueles que

\footnotetext{
${ }^{4}$ Grifo nosso.
} 
ali habitam, caracterizando seus hábitos e costumes como sendo típicos do "homem pantaneiro". Esse "pantaneiro", segundo Pinto e Lacerda, estabelece a sua própria classificação

Para eles existem os pantanais do Rio Negro, do Aquidauana, do Miranda, do Abobral, do Apa, do Tereré e do Jacadigo, levando-se em conta em quase todos, o papel exercido pelos rios. Entretanto em Mato Grosso do Sul, a divisão mais conhecida e/ou cotada é a seguinte: Pantanal do Aquidauana, do Paraguai, de Nhecolândia, do Abobral, do Miranda, do Nabileque e do Paiaguás. (PINTO E LACERDA,2013, p. 97).

Estes sujeitos denominados "Pantaneiros", habitam esta região do pantanal, convivem em uma região de clima úmido ou seco e acabam por compartilhar hábitos e costumes que são típicos da região. 0 clima do Pantanal se caracteriza por ser quente e chuvoso no verão e frio e seco no inverno. O nome Pantanal se deve a isso, na época das chuvas, intransitável por terra e na época da seca, no inverno, o rio seca, e só o que sobra é o barro. A característica marcante, que é unânime entre os pesquisadores que se dedicam a investigar a cultura pantaneira, é a estreita relação do pantaneiro com a natureza.

Dentre os hábitos e costumes, estão as rodas de tereré, sempre ao ar livre, uma vez que como já dito anteriormente o contato com a natureza é primordial na cultura pantaneira.

O tereré é tomado antes do almoço e no meio da tarde. A preparação do tereré, quando tomado nos momentos de lazer, constitui-se em um verdadeiro cerimonial com regras pré-estabelecidas: Forma-se uma roda em torno do cevador (aquele que serve) e a guampa de mate (copo feito de cuia do pescoço da cabaça ou do chifre de boi), a roda do tereré gira sempre em sentido horário, não sendo permitida a interrupção desse movimento, aquele que chega, ocupa sempre a última posição sentando no final da roda. Ao sentir-se saciado, o peão deve sempre agradecer ao "cevador" passando a sua veza outro sem, contudo, sair da roda. Essas rodas constituem também em rodas de prosa, onde contam as agruras do trabalho do dia, as piadas e os "causos" pantaneiros, que sempre envolvem muita valentia na narrativa. (FERRO et al, 2013, p. 176-177)

As rodas de tereré se caracterizam como um momento de interação social, em todos os espaços seu consumo é permitido, nas Universidades, no comércio. A cuia, ou muitas vezes um copo de alumínio, utensilio utilizado para substituir a cuia, passa de mão em mão e de boca em boca a bebida é sorvida, compartilhada. A bebida que é tradicional em Mato Grosso do Sul é considerada Patrimônio Imaterial da Humanidade e símbolo do Paraguai, um dos países vizinhos. Parece um tanto inusitado que estejamos trazendo para a discussão um costume, um hábito considerado popular entre um grupo de pessoas de uma determinada cultura, mas como aborda Eagleton (2005, p.17),

Outro ganho histórico da teoria cultural foi estabelecer que a cultura popular também merece ser estudada. Com algumas honrosas exceções, o pensamento acadêmico tradicional ignorou, durante séculos, a vida diária das pessoas comuns. Na verdade, ignorava mesmo era a própria vida, não apenas a diária.

E sem deixar de enfatizar que esta reflexão está imbricada em nosso objeto de estudo, a identidade cultural dos sujeitos pantaneiros e o processo de disciplinamento a que seus corpos foram submetidos quando do estabelecimento do contexto da pandemia da Covid-19.

\subsection{A disciplina imposta pela pandemia, as necessárias mudanças de hábitos ou: "aquilo que ousamos chamar de elasticidade do social"}

Embora nós seres humanos tenhamos alguma dificuldade em perceber nossa qualidade de sujeitos históricos, pois costumamos passar pela vida quase como espectadores e, com bastante menos 
frequência, algum episódio excepcional afasta a existência de uma sorte de linearidade pela qual a vida transita.

Contudo, poucas vezes a humanidade toda foi sacudida por algum fato que envolvesse a todos sem distinção como aconteceu no início da década do 2020, quando a humanidade vivenciou uma das maiores pandemias já experimentadas, a da COVID 19, doença que dizimou como poucos eventos anteriores nossa espécie, máxime considerando que o mundo vive o auge da tecnologia e a ciência médica progrediu como poucas vezes no final do século anterior e no início deste em curso.

As mudanças trazidas pela pandemia, exigiram muito mais que mudanças de hábitos e comportamentos, exigiu que nos reinventássemos e nos "disciplinássemos" para nos adequarmos a situação de calamidade que assolou a humanidade devido a letalidade do vírus. Foucault, no entanto, nos fala, que não é a primeira vez que o corpo é objeto de um processo de disciplinamento.

A escala, em primeiro lugar, do controle: não se trata de cuidar do corpo, em massa, grosso modo, como se fosse uma unidade indissociável, mas de trabalha-lo detalhadamente; de exercer sobre ele uma coerção se folga, de mantê-lo ao nível da mecânica - movimentos, gestos, atitudes, rapidez, poder infinitesimal sobre o corpo ativo. $\mathrm{O}$ objeto, em seguida, do controle: não ou mais, os elementos significativos do comportamento ou a linguagem do corpo, mas a economia, a eficácia dos movimentos, sua organização interna, a coação se faz mais sobre as forças do que sobre os sinais, a única cerimônia que realmente importa é a do exercício. (FOUCAULT, 2014, p.118)

E porque se fez importante esse disciplinamento? Porque estamos vivendo algo nunca experimentado por nossas gerações, porque negligenciar este momento, não manter os cuidados necessários já contribuiu para ceifar a vida de muitas pessoas. E como destaca Foucault (2014) a disciplina procede a distribuição dos indivíduos no espaço, esse espaço que antes era ocupado por todos, agora necessita de uma "cerca", um local fechado, onde os sujeitos possam se proteger desse vírus invisível e proteger aqueles que the são caros.

Mas quando se fala em disciplina, ela não está apenas ligada aos espaços que podemos ou não circular, mas também na maneira como nossos comportamentos necessitam se modificar, se disciplinar, devido a termos nos deparado com a fragilidade de nossos corpos. E para sermos solidários uns com os outros necessitamos aderir a essa disciplina.

Mas, Santos (2020), nos alerta dos processos discriminatórios que esse disciplinamento pode representar para muitos grupos sociais nesse período. E nos apresenta grupos que ao longo dos tempos foram vítimas de exploração e dominação, sejam elas pelo sistema capitalista, pelas questões de discriminação racial e sexual. Segundo Santos (2020) fazem parte desse grupo, as mulheres, os trabalhadores de rua, os moradores de rua por sua vulnerabilidade, os moradores das periferias e lugares mais pobres das cidades, os deficientes e os idosos.

\subsection{As particularidades da identidade cultural dos sujeitos: Reconstruindo-se para não se descontruir}

Abordar sobre identidade, seu conceito ou como se constrói uma identidade, ainda mais quando se trata de identidade cultural nos parece um tema inquietante, provocador e hodierno.

Uma vez que se ingressa na vida adulta precisamos nos posicionar, nos definir, assumir uma "identidade", seja ela pessoal e/ou profissional, Hall (2011), nos apresenta três concepções de 
identidade. A de sujeito do Iluminismo, de sujeito sociológico e sujeito pós-moderno. Este sujeito do iluminismo, conforme Hall (2011) é aquele cuja concepção se baseia totalmente na pessoa humana, centrada, unificada e dotada de capacidades, ou seja, o sujeito que iniciamos nossas considerações acima, um sujeito que nasce, cresce e se desenvolve. Uma visão individual de construção da identidade.

Já o sujeito sociológico que Hall (2011) nos apresenta, é aquele sujeito que reflete a complexidade do mundo moderno, este sujeito necessitava da relação com as outras pessoas para a formação da sua identidade. Uma visão de interação, o eu e a sociedade.

De acordo com essa visão, que se tornou a concepção sociológica clássica da questão, a identidade é formada na "interação" entre o eu e a sociedade. O sujeito ainda tem um núcleo ou essência interior que é o "eu real", mas este é formado e modificado num diálogo contínuo com os mundos culturais "exteriores" e as identidades que esses mundos oferecem. A identidade, nessa concepção sociológica, preenche o espaço entre $o$ interior e o exterior - entre o mundo pessoal e o mundo público. 0 fato de que projetamos a nós próprios nessas identidades culturais, ao mesmo tempo que internalizamos seus significados e valores, tornando-os parte de nós, contribui para alinhar nossos sentimentos subjetivos com os lugares objetivos que ocupamos no mundo social e cultural. A identidade, então costura (ou, para usar uma metáfora médica, "sutura") o sujeito a estrutura. (HALL, 2011, p.12)

Mas quando nos reportamos a terceira concepção de identidade, a de sujeito pós-moderno, é que nos deparamos com a mudança, com o processo de fragmentação da construção dessa identidade. O sujeito pós-moderno tem sua identidade formada e transformada continuamente (HALL,2011). Tudo se modifica, tudo se transforma ao nosso redor, impossível afirmarmos que teremos uma identidade única, que seremos os mesmos. Existem fatos, acontecimentos, que corroboram para que essa transformação aconteça. "A questão da identificação nunca é a afirmação de uma identidade pré dada, nunca uma profecia auto cumpridora, é sempre a produção de uma imagem de identidade e a transformação do sujeito ao assumir aquela imagem". (BHABHA,1998, p.76)

A determinação de identidade, nem sempre passa pelos elementos ou questões mais visíveis, até porque atendendo as variadas dimensões que cada sujeito apresenta na construção de sua identidade, étnico racial, social, política, religiosa, não é muito fácil identificar qual destas é a que vai prevalecer ou vai ser a soma de todas estas que vai prevalecer. Mas o que nos impele aqui é justamente refletir como esse sujeito "fragmentado"5 define sua identidade a partir da sociedade em que está inserido, como os costumes, a cultura, os hábitos de uma região fazem com esse sujeito se reconheça como parte daquele lugar. Hall (2011), nos fala sobre as culturas nacionais e a produção de identidades.

As culturas nacionais são compostas não apenas de instituições culturais, mas também de símbolos e representações. Uma cultura nacional é um discurso- um modo de construir sentidos que influencia e organiza tanto nossas ações quanto a concepção que temos de nós mesmos. As culturas nacionais, ao produzir sentidos sobre a "nação", sentidos com os quais podemos nos identificar, constroem identidades. Esses sentidos estão contidos nas histórias que são contadas sobre a nação, memórias que conectam seu presente com seu passado e imagens que dela são construídas. (HALL,2011, p.51)

As culturas, os modos de sobrevivência de uma sociedade, os modos de pensar, todos compõem e definem identidades, nestes tempos foi necessário todo um processo de reconstrução dessas

\footnotetext{
${ }^{5}$ Expressão utilizada por Hall, Stuart (2011). A identidade Cultural na Pós-modernidade.
} 
identidades culturais para que as sociedades se adaptassem a novos modos de viver e conviver. Bhabha (1998), nos fala das singularidades, das ambivalências e dos entre lugares que dão início a novos signos de identidade e acabam por construir ou quem sabe reconstruir a própria ideia de sociedade e de relações sociais

\section{CONSIDERAÇÕES SOBRE O CAMINHO METODOLÓGICO}

Os sujeitos da pesquisa responderam a um número de dez questões através do Google Forms. A amostra foi aleatória, dividida em randômica simples, pois cada sujeito da população pesquisada teve a mesma chance de ser escolhido. Trata-se de uma pesquisa com perspectiva etnometodologica. A Etnometodologia é o estudo das atividades cotidianas, quer sejam triviais ou eruditas como nos referencia, COULON (1995). Vale enfatizar que a Etnometodologia é importante para o conhecimento de culturas diferentes, que também é um dos objetos deste estudo e que isto é importante para compreender e respeitar as diferentes culturas existentes e como cada grupo social reage frente aos impactos causados por fenômenos externos.

Trata-se de uma pesquisa de natureza básica de abordagem qualitativa. Para Minayo (2001), a pesquisa qualitativa trabalha com o universo de significados, motivos, aspirações, crenças, valores e atitudes, o que corresponde a um espaço mais profundo das relações, dos processos e dos fenômenos que não podem ser reduzidos à operacionalização de variáveis. Do ponto de vista dos procedimentos técnicos esta pesquisa contou com a pesquisa bibliográfica, aliada a Etnometodologia. "A pesquisa bibliográfica é desenvolvida a partir de material já elaborado, constituído de livros e artigos científicos". (GIL, 2008, p.50).

Quanto a universo, população e amostra, nosso universo são os docentes e discentes do Ensino do Superior do bioma pantanal sul mato-grossense, a população são os docentes e discentes do Ensino do Superior do bioma pantanal sul mato-grossense da Universidade Federal de Mato Grosso do Sul, Campus de Aquidauana, município localizado na Mesorregião dos Pantanais Sul-Mato-Grossenses e a Microrregião de Aquidauana. Situada na Serra de Maracaju a $139 \mathrm{~km}$ de capital de Mato Grosso do Sul, e 203 km de Bonito, a cidade de Aquidauana compreende a área norte do Estado, desde o Morrinho do Pimentel, na divisa com Corumbá e Rio Verde até Anastácio, ao sul.

A amostra foi de 133 (centro e trinta e três) participantes da pesquisa, que compreendeu, discentes e docentes. Cabe enfatizar que uma amostra costuma ser considerada representativa do universo ou da população pesquisada o que entendemos aqui ser uma parcela significativa.

\section{RESULTADOS E DISCUSSÃO}

$\mathrm{Na}$ realização da pesquisa, participaram docentes e discentes do Ensino Superior da região pertencente ao bioma pantanal. Os sujeitos participantes da pesquisa responderam a um questionário que Ihes foi enviado via Google Forms, com os devidos esclarecimentos de sigilo e confiabilidade. Não houve nenhum contato físico entre os pesquisadores e os sujeitos da pesquisa. Dentre as questões que foram respondidas na pesquisa, as questões de número 01 a 05 estão relacionadas aos costumes da região pantaneira, que também podem ser caracterizados como parte do lazer dos sujeitos. A questão de número 06 aborda sobre o impacto dos efeitos da pandemia na motivação dos sujeitos para o desenvolvimento de suas atividades acadêmicas e profissionais. As questões 07 e 08 abordam sobre o afastamento das atividades em contato com a natureza e a permanência de longos períodos 
dentro de casa. Enfatizando se estes períodos foram responsáveis por mudanças no relacionamento com a família.

Já as questões de número 9 e 10, encerram os questionamentos promovendo um olhar sobre a saúde emocional dos participantes da pesquisa e de como podemos considerar que a pandemia da Covid19 nos "disciplinou", nos "ensinou" novas formas de viver e de nos relacionarmos.

Os resultados referentes ao bloco de questões de 1 a 5 , que se referem a cultura e as atividades de lazer podemos destacar a questão de número de três, onde foi questionado aos sujeitos da pesquisa se estes cultivam o hábito considerado típico da cultura pantaneira de tomar a bebida chamada Tereré. Os resultados demonstram que a maioria já não mantem o hábito, embora não seja um percentual muito expressivo, 36,4\% respondeu que não e 30,3\% respondeu ainda manter o consumo da bebida. Já $18,2 \%$ dizem que consome pouco e 15,2\% raramente experimenta a bebida.

Na questão de número quatro, os percentuais demonstram que a mudança aconteceu também na forma como a bebida é consumida, uma vez que como já referenciamos anteriormente, o consumo originalmente acontecia em família antes do almoço e no meio da tarde, esta opção atingiu um percentual de $34,8 \%$. Com a família e com os amigos os percentuais chegaram a $21,7 \%$. Mas o mais surpreendente e que denota a interferência da pandemia nos costumes é que $43,5 \%$ dos sujeitos da pesquisa declararam que optaram por manter a tradição sozinhos.

Poucas vezes a humanidade viveu um fato que envolvesse a todos sem distinção como o que aconteceu no início do ano de 2020, quando vivenciamos uma das maiores pandemias já experimentadas, a da COVID- 19, doença que dizimou como poucos eventos anteriores a nossa espécie. Para ratificar o resultado do questionamento anterior, foi interpelado aos participantes da pesquisa se a pandemia impôs mudanças nos seus hábitos relacionados ao consumo de Tereré, o que responderam, afirmativamente um percentual de $43,3 \%$, que não ocorreu nenhuma mudança em seus hábitos $26,7 \%$. O interessante é que somente um percentual de $13,3 \%$ diz ter modificado radicalmente seus hábitos, ficando cada um com seu copo e sua bomba para o consumo, 16.7\% dizem continuar compartilhando com as pessoas da família.

A pergunta que inquere sobre como se mantiveram estimulados para permanecer desenvolvendo suas atividades profissionais e acadêmicas, desde o início da Pandemia, revelou que 69,7\% viam-se alternando períodos de motivação com períodos de desmotivação, ao que 15,2\% afirmam manteremse todo o tempo motivados. Já 9,1\% responderam que perdeu totalmente a motivação profissional e acadêmica desde o início do contexto de pandemia até os dias atuais e 6,1\% dos respondentes alega não ter sentido nenhuma mudança quanto as suas motivações.

Existem outros grupos sociais para os quais, a esperança excede o medo numa tal proporção que o mundo lhes é oferecido como um campo de possibilidades [...]. Em tempos normais, a maioria dos grupos sociais vive entre os dois extremos. As suas vidas são marcadas por mais ou menos medo, mais ou menos esperança [...]. (SANTOS,2019, p.407-408)

Já que a pandemia trouxe mais períodos dentro de casa, longe da natureza consultamos aos participantes da pesquisa se ficar mais tempo em casa interferiu no seu estado emocional. As respostas nos mostraram que 37,5\% disseram que sim, $21,9 \%$ afirmaram que não houve nenhuma interferência em seu estado emocional e 40,6\% disse sentir-se um pouco abalado emocionalmente por não manter a rotina de passeios em que o contato com a natureza eram o objetivo principal. 
Considerando que somos seres ativos, sociais e históricos entendemos que os resultados nos mostram que existem formas de perceber e se adequar diante das mais diversas situações.

Ao serem questionados sobre se as relações com a família nos períodos de isolamento social sofreram alguma mudança, o resultado expresso, deixa claro que sim, um número massivo dos sujeitos participantes da pesquisa, acredita que as relações familiares sofreram interferência nesse período de isolamento social, $73,3 \%$ responderam afirmativamente, sentiram que houve alteração nas relações familiares, $16,7 \%$ acreditam que houve pouca mudança nas relações e somente $10 \%$ dos participantes acredita que não ocorreu nenhuma mudança. Este é um resultado que preocupa pois conforme as palavras de Santos (2020),

O aumento do número de divórcios em algumas cidades chinesas durante a quarentena pode ser um indicador do que acabo de dizer. Por outro lado, é sabido que a violência contra as mulheres tende a aumentar em tempos de guerra e de crise - e tem vindo a aumentar agora. Uma boa parte dessa violência ocorre no espaço doméstico. O confinamento das famílias em espaços exíguos e sem saída pode oferecer mais oportunidades para o exercício da violência contra as mulheres. (SANTOS, 2020, p.16)

Quando o assunto são as emoções, os sujeitos das pesquisas não hesitaram, 90,9\% responderam afirmativamente, a saúde emocional ficou abalada durante o período do isolamento imposto pela pandemia. Segundo Bock (2018, p. 194), "as emoções são expressões afetivas acompanhadas de reações intensas e breves do organismo em resposta a um acontecimento inesperado, ou, muito aguardado". Certamente no caso de nossa pesquisa, trata-se realmente de um acontecimento extremamente inesperado e as emoções de toda a humanidade foram alteradas significativamente.

A última questão, indaga se foi perceptível que nesse período tivemos que nos "disciplinar", "reaprender", uma nova forma de viver e de nos relacionarmos, o que 93,9\% responderam que sim e apenas $6,1 \%$ entendem que somente um pouco de disciplina e aprendizado se fez necessário para nos adaptarmos a este novo contexto. Para Santos (2019), o conhecimento não é possível sem experiência, e é através do conhecimento que podemos nos abrir ao mundo. E conhecer e viver todo esse processo nos permitiu e permitirá reaprender novas formas de viver e de nos relacionarmos. $\mathrm{E}$ como somos sabedores de que reaprendendo a conviver, podemos ter renovada a esperança, recorremos mais uma vez a Santos que traz uma provocação ao falar sobre esse processo utilizando a relação entre o medo e a esperança.

O medo e a esperança não são distribuídos de forma igual por todos os grupos sociais ou períodos históricos. Existem grupos sociais nos quais o medo se sobrepõe a esperança numa tal proporção que 0 mundo acontece a essas pessoas sem que tenham a possibilidade de fazer acontecer o mundo. (SANTOS, 2019, p. 407)

Impossível não aprender em situações extremas como esta que estamos vivendo desde o início do ano de 2020, impossível não repensar nossas relações sociais, nossa forma de ver e estar no mundo.

\section{CONSIDERAÇÕES FINAIS}

A articulação que buscamos realizar entre saúde, educação e o processo de disciplinamento dos corpos imposto pela pandemia nos levou por caminhos de diferentes vertentes. Uma lição fica meridianamente clara, se até antes desta emergência uma crítica recorrente aos relacionamentos era o afastamento dos indivíduos do convívio imediato, produto do apego destes às tecnologias, foram estas mesmas tecnologias que propiciaram a conexão entre as pessoas, principalmente no âmbito 
educacional e no social, impedindo que o longo período de isolamento não fosse tão radical, o que não deixa de ser, ao fim das contas, uma quebra de paradigma.

O problema de pesquisa que propomos centrou-se em como os sujeitos da pesquisa que estavam acostumados a ter o hábito do contato direto com o outro, através de costumes que são próprios de sua organização social, como as rodas de Tereré, os encontros em festas típicas da região, as reuniões ao ar livre, lidaram e lidam com seus sentimentos e qual a influência desse afastamento de uma vida social culturalmente institucionalizada na região do Pantanal, no desempenho profissional e educacional desses sujeitos. Os resultados da pesquisa nos remeteram para o fato de que a mudança de hábitos se fez necessária, a busca por um reordenamento, o necessário "disciplinamento" dos corpos dos sujeitos para assumir assim uma posição de preservação.

Dentre os objetivos, buscamos identificar como esse processo de disciplinamento de corpos se dá, como respondem a esse processo que foi imposto, a essa mudança que, de repente, trouxe mais períodos dentro de casa, longe da natureza, percebemos que mesmo sentindo falta desse contato com a natureza, o entendimento mudou, os sujeitos da pesquisa se mostraram atentos a necessidade de reaprender novas formas de lazer e como corrobora Santos (2020), o momento agora é de imaginar o planeta como a nossa casa comum e a natureza como a nossa mãe originária a quem devemos amor e respeito. A natureza não nos pertence, somos nós que pertencemos a ela.

Quanto ao objetivo de verificar como e se as relações com a família nos períodos de isolamento social promoveram alguma interferência no estímulo para permanecer desenvolvendo suas atividades profissionais e acadêmicas, percebe-se que ocorreram mudanças nestas relações. Os longos períodos em casa tendem a expor nossas fragilidades a nos colocar frente a frente conosco mesmo, com nossos sentimentos e com aqueles que víamos muitas vezes só de passagem, apesar de dividirmos o mesmo espaço. Na busca por identificar as dificuldades apresentadas pelos sujeitos participantes da pesquisa (discentes/docentes) no processo de ajustar o próprio corpo aos imperativos temporais do período vivenciado, nos deparamos com sentimentos como medo, esperança e a ideia de que novas articulações de preservação das relações então sendo construídas.

Dessa forma entendemos que a pesquisa atingiu ao que se propôs, apresentar um recorte entre a relação saúde, educação e a disciplina que nos foi imposta pela Pandemia na tentativa de promover um olhar sobre o que discentes e docentes do Ensino Superior da região do Pantanal sul matogrossense, enfatizando os desafios da contemporaneidade no campo do lazer esperam do que, como nos traz Boaventura (2020), ficou convencionado chamar de "novo normal". E como este mesmo autor nos fala em seu livro "A cruel Pedagogia do Vírus", escrito no ano de 2020, também estamos certos de que esta pandemia nos dará mais lições no futuro, o reinventar-se, palavra muito utilizada nestes tempos, nos mostrou que somos sim capazes de aprender e de nos reordenarmos entre processos políticos, civilizatórios e culturais por uma sociedade melhor.

\section{REFERÊNCIAS}

BHABHA, Homi K. O local da Cultura. Belo Horizonte, Editora UFMG,1998.

COULON, Alain. Etnometodologia e Educação. Petrópolis: Vozes, 1995.

BOCK, Ana Mercês Bahia. FURTADO, Odair. TEIXEIRA, Maria de Lourdes Trassi. Psicologias. Uma introdução ao estudo de Psicologia. São Paulo, Editora Saraiva, 2018. 
FERRO, Olga Maria dos Reis et al. Aspectos da Cultura do Homem Rural Pantaneiro. In: FERRO, Olga Maria dos Reis. LOPES, Zaira de Andrade (Orgs). Educação e Cultura: Lições Históricas do Universo Pantaneiro. Campo Grande, Mato Grosso do Sul, Editora da UFMS, 2013.

FOUCAULT, Michel. Vigiar e punir. Nascimento da prisão. Petrópolis, Editora Vozes,2014.

GIL, Antônio Carlos. Métodos e Técnicas de Pesquisa Social. São Paulo, Editora Atlas, 2008.

HALL, Stuart. A identidade Cultural na Pós-modernidade. Rio de Janeiro. DP\&A,2011.

MARCONI, Marina de Andrade. PRESOTTO, Zelia Maria Neves. Antropologia: Uma Introdução. São Paulo, Editora Atlas, 2005.

MINAYO, M. C. S. (Org.). Pesquisa social: teoria, método e criatividade. Petrópolis, Vozes, 2001.

NOGUEIRA, Albana Xavier. A linguagem do homem pantaneiro. Tese de Doutorado. Assis, São Paulo. UNESP, 1989.

PINTO, Maria Leda. LACERDA, Léia Teixeira. A Pedagogia Pantaneira e o Discurso estético de Manoel de Barros e Abílio Leite de Barros na preservação ambiental: memórias e tradições culturais sul-mato-grossenses. In: FERRO, Olga Maria dos Reis. LOPES, Zaira de Andrade (Orgs). Educação e Cultura: Lições Históricas do Universo Pantaneiro. Campo Grande, Mato Grosso do Sul, Editora da UFMS, 2013.

SANTOS, Boaventura de Sousa. A Cruel Pedagogia do Vírus. Coimbra. EDIÇÕES ALMEDINA, S.A., 2020.

SANTOS, Boaventura de Sousa. O fim do Império Cognitivo. A afirmação das Epistemologias do Sul. Belo Horizonte. Autêntica Editora, 2019.

https://www.planalto.gov.br/ccivil_03/_ato2007-2010/2007/decreto/d6040.htm Política Nacional de Desenvolvimento Sustentável dos Povos e Comunidades Tradicionais. Acesso em maio de 2021.

https://www.gov.br/saude/pt-br/coronavirus/o-que-e-o-coronavirus Acesso em julho de 2021

https://www.paho.org/pt/covid19/historico-da-pandemia-covid-19 Acesso em julho de 2021.

https://bvsms.saude.gov.br/novo-coronavirus-covid-19-informacoes-basicas/ Acesso em julho de 2021.

Submissão: 08/08/2021

Aceito: 18/08/2021 